\title{
Escrivão de prosas. Contadora de histórias. Um diálogo entre narrativas.
}

Maria Ignês Carlos Magno

Doutora em Ciências da Comunicação pela ECA/USP

e professora do curso de Pedagogia do Centro Universitário Salesiano

de São Paulo e da Universidade Anhembi Morumbi

E-mail: unsigster@gmail.com

Penetra surdamente no reino das palavras. Lá estão os poemas que esperam ser escritos.

Estão paralisados, mas não há desespero,

há calma e frescura na superfície inata.

Ei-los sós e mudos, em estado de dicionário.

Convive com teus poemas, antes de escrevê-los.

Tem paciência, se obscuros. Calma, se te provocam.

Espera que cada um se realize e consume

Com seu poder de silêncio ${ }^{1}$.

A idéia inicial para essa Videografia era a de selecionar um filme de cada continente, com diferentes assuntos, para que o professor tivesse um número maior de temas para utilizar em seus cursos. Feita a seleção, veio o momento de ver e rever cada um dos filmes escolhidos para propor alguns caminhos de leitura e de atividades, como é a proposta desta seção. Anotações feitas. Fichas técnicas organizadas e um outro início. Só que esse, diferentemente do outro, conduzia meus pensamentos para o poema de Carlos Drummond de Andrade:

Não faças versos sobre acontecimentos. Não há criação nem morte perante a poesia... Penetra surdamente no reino das palavras. Lá estão os poemas que esperam ser escritos. ${ }^{2}$

Palavras. Escrituras. Palavras faladas. Palavras escritas. Palavras em estado de dicionário à espera de escrituras: históricas, proféticas, poéticas. Palavras/imagens na narrativa cinematográfica. Palavras para serem lidas e ouvidas. Imagens para serem vistas.

Como o olhar e o pensamento não são neutros, igual aos olhares dos autores e dos narradores, optei pelos filmes Narradores de Javé, de Eliane Caffé,

1. ANDRADE, Carlos Drummond de. Procura da poesia: poesia e prosa. Rio de Janeiro: Nova Aguilar, 1988. p. 212-214.

2. Ibidem. 
e Um filme falado, de Manoel de Oliveira e as narrativas de ambos como foco. A tentativa é mostrar os diálogos existentes entre diferentes narrativas; as confluências entre a narrativa cinematográfica e as estruturas das narrativas literárias, as possibilidades de pensar sobre as línguas e sobre as escritas que falam e escrevem as histórias e as prosas do mundo.

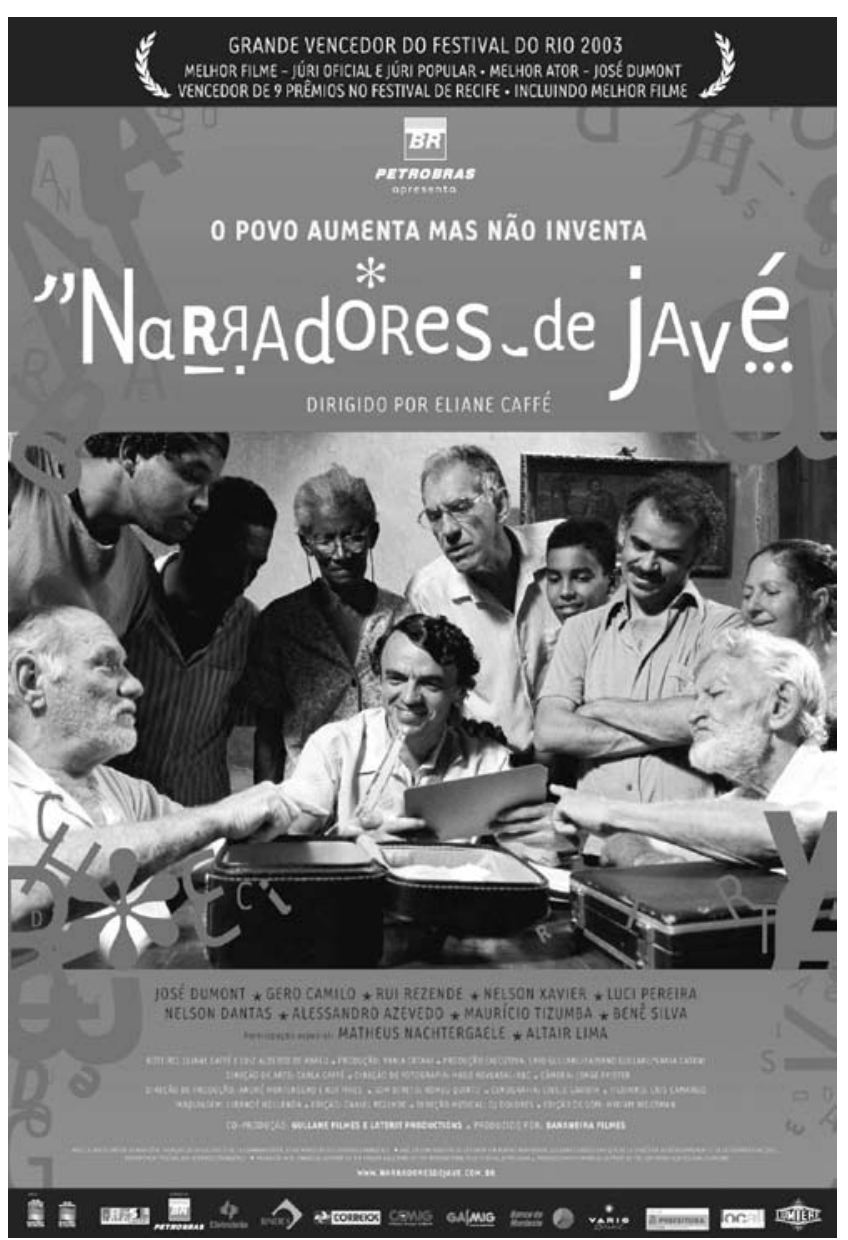

\section{FICHA TÉCNICA}

Narradores de Javé

Direção - Eliane Caffé

Roteiro - Luiz Alberto

de Abreu e Eliane Caffé

Produção - Vânia Catani

Música - DJ Dolores e

orquestra Santa Massa

Fotografia - Hugo Kovensky

Direção de arte - Carla Caffé

Ano - 2003

Duração - 100 minutos

Após saberem que a cidade onde vivem será inundada para a construção de uma hidrelétrica, os moradores adotam uma ousada estratégia...

Somente uma ameaça à própria existência pode mudar a rotina dos habitantes do pequeno vilarejo de Javé. É aí que eles se deparam com o anúncio de que a cidade pode desaparecer sob as águas de uma hidrelétrica. Em resposta à notícia devastadora, decidem preparar um documento contando os grandes acontecimentos heróicos do local para que Javé possa escapar da destruição.

Como a maioria dos moradores é analfabeta, a primeira tarefa é encontrar alguém que possa escrever as histórias. O único morador letrado e capaz de registrá-las é Antonio Biá, um habitante controverso. 


\section{FICHA TÉCNICA}

Um filme falado

Direção e Roteiro - Manoel de Oliveira

Produção - Paulo Branco

Fotografia - Emmanuel Machuel

Montagem - Valérie Loiseleux

Países - Portugal/França/Itália

Ano - 2003

Duração - 96 minutos

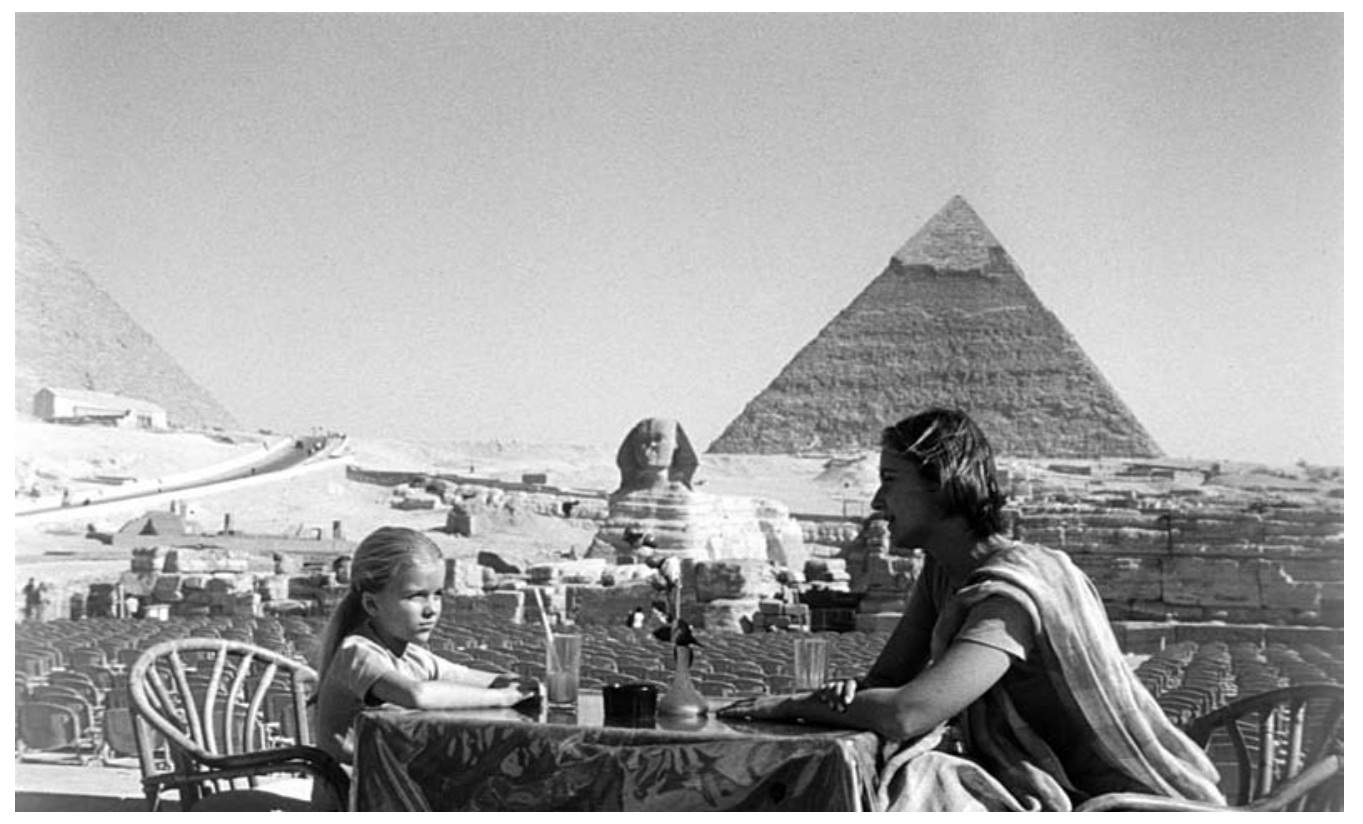

Em Um filme falado, Rosa Maria e a filha Maria Joana representam a confluência e a exclusão de personagens em relação à fala.

Rosa Maria, uma jovem professora de História, embarca com a filha em um cruzeiro. O navio sai de Lisboa e atravessa o mar Mediterrâneo com destino a Bombaim, na Índia, onde seu marido a espera. Durante a travessia, ela visita pela primeira vez Marselha, as ruínas de Pompéia, Ceuta, Atenas, as pirâmides do Egito e Istambul. Lugares que representam culturas que marcaram a civilização ocidental. A viagem transcorria bem até que uma estranha ameaça perturba o cruzeiro e a vida dos passageiros, quando o navio atravessa o Golfo Pérsico.

\section{SOBRE A HISTÓRIA FALADA E A HISTÓRIA ESCRITA}

Entre os muitos aspectos que Narradores de Javé e Um filme falado nos chamam a atenção, um deles é a diferença dos personagens em relação à fala. Enquanto os moradores de Javé, por terem na urgência dos relatos a salvação de sua história, falam todos ao mesmo tempo, porque a memória está contida na fala, a fala de Rosa Maria, mãe de Maria Joana, é quase um monólogo que 
acompanha o movimento das ondas, provocado pela quilha do navio, toda vez que passam por uma cidade ou um monumento historicamente construído e preservado durante os séculos de civilização européia.

Outro aspecto que se evidencia é o fato de os primeiros personagens serem analfabetos, e a segunda personagem possuir a erudição do conhecimento histórico registrado nos documentos escritos e de falar vários idiomas. Entre o analfabetismo e o letramento, entre o arcaico e o erudito, dá-se uma interessante confluência dos dois povos representados pelo cinema português e brasileiro.

Confluências não só históricas, se pensarmos que o Brasil foi colonizado pelos portugueses e que parte de nosso subdesenvolvimento construiu-se durante os séculos de colonização, mas a confluência ao mesmo tempo da competência e da exclusão. Paradoxalmente, tanto os analfabetos de Javé como a erudita Maria Rosa possuem conhecimento e competência histórica e lingüística. Os narradores de Javé, mesmo analfabetos e tendo suas memórias históricas atreladas à fala, são excluídos do mundo letrado. Maria Rosa, ainda que domine a escrita, o conhecimento dos livros e fale diferentes línguas, é excluída do universo lingüístico dos lugares visitados: em Marselha, para se fazer entender, fala o francês; na Grécia e no navio, ora fala o inglês, ora o francês. O português, sua língua natal, só é compreendido pela filha ou, quando encontra, no Egito, um ator conterrâneo que participa da conversa entre mãe e filha.

Se considerarmos que os dois filmes têm na palavra falada a chave da trama histórica, porém necessitam de registro escrito para existirem, porque a ciência da história pede documentos escritos que possam ser comprovados, vale discutir um pouco o significado da palavra escrita na história da humanidade.

Clarisse Herrenschmidt, especialista da civilização aquemênida e da religião masdeísta, inicia o texto $O$ todo, o enigma e a ilusão dizendo que a escrita foi uma invenção extraordinária porque tornou a linguagem visível; esclarece, entretanto, que isso não aconteceu de forma homogênea. Algumas escritas tornaram visível um objeto, uma coisa do mundo já visível; outras tornam visível uma palavra, uma sílaba, um som, uma coisa da linguagem até então apenas audível e pronunciável.

Para a autora:

O contexto da escrita não se define como o que a cerca e a torna possível: caneta, tabuinha ou memória central; ele é uma rede em que a escrita se prende e estende, por sua vez, sobre onde estamos: a relação das coisas da linguagem com as coisas do mundo, instalada pela língua dentro do homem, uma relação imediata, quase sensível, que estabelece uma identidade necessária, sempre, cada dia, representada - e todavia falaciosa. O contexto da escrita é o homem na linguagem e no mundo ${ }^{3}$.

3. HERRENSCHMIDT, Clarisse. O todo, o enigma e a ilusão. In: BOTTÉRO, Jean; MORRISON, Ken et al. Cultura, pensamento e escrita. São Paulo: Editora Ática, 1995. p. 102.
Jean Bottéro, ao falar da revolução ocorrida na história humana após a invenção da escrita, analisa, entre outros aspectos, a revolução provocada na área da comunicação e a qualidade de suas mensagens, fazendo uma leitura comparativa entre o discurso oral e o escrito. 
Embora fique clara no texto de Bottéro a defesa da palavra escrita, acredito que seja interessante pontuarmos algumas colocações do autor obre o discurso oral e o escrito. Para ele:

A oralidade implica a presença simultânea, no tempo e lugar, da boca que fala e dos ouvidos que ouvem. Já o discurso escrito transcende o espaço e a duração: uma vez fixado, pode, por si mesmo, ser difundido por inteiro em todos os lugares e todos os tempos, em toda parte onde encontra um leitor, bem além do círculo obrigatoriamente estreito dos "auditores". Dispensa a presença daquele que o fez e suprime, na sua comunicação, a dependência auricular daquele que recebe [...]. Tornou-se um objeto, coerente, autônomo e manipulável. Como tal, podemos não só examiná-lo sob todas as suas costuras, mas também recortá-lo, analisá-lo como qualquer amostra $[\ldots]^{4}$.

Outro ponto de confluência entre as histórias narradas diz respeito ao mito fundador e às narrativas lendárias.

Rosa Maria, ao mostrar para a filha o monumento erguido em homenagem a Dom Henrique, ou O Infante Navegador, como ficou conhecido por ter iniciado as grandes conquistas portuguesas na África, passa a narrar a história da expansão colonizadora de Portugal desde Ceuta, no norte da África, em 1415, e marco da expansão portuguesa pelo litoral africano - para descobrir uma rota marítima para as Índias, até a Batalha de Alcácer-Quibir, em Marrocos -, quando Dom Sebastião e quase todos seus soldados morreram ou se tornaram prisioneiros do exército muçulmano.

Ao chamar a atenção da filha para o nevoeiro que cobria a região, Rosa Maria conta a história do rei morto em combate e explica por que ele ficou conhecido como $O$ Encoberto, originando o mito de Dom Sebastião e o sebastianismo em Portugal.

Rei da segunda Dinastia e $16^{\circ}$ Rei de Portugal, ele governou entre 1557 e 1578. Católico, sonhador e influenciável, seu modelo de governo era o dos heróis e guerreiros. Ao completar 24 anos, partiu com um grande exército para Marrocos com o objetivo de combater os infiéis e conquistar os muçulmanos. Ignorando os perigos do combate no interior do país inimigo, Dom Sebastião empreendeu a batalha, sendo derrotado e morto.

Embora a população soubesse que o rei havia morrido, aqueles que voltaram diziam não ter visto o corpo dele. Como era solteiro e não possuía herdeiros, o trono português passou para Felipe II, espanhol e neto de Dom Manuel. O povo não aceitou a morte do rei e durante anos acreditou que Dom Sebastião regressaria a Portugal numa noite de nevoeiro. Para o povo, sua alma tomaria forma e voltaria para reclamar o trono e a independência de Portugal.

Em Narradores de Javé, os moradores também precisavam de um herói, de um guerreiro, misto de conquistador e salvador. A verdade é que necessitavam de dois salvadores: o outro seria a figura de Biá, único letrado capaz de escrever a saga, cujo título da primeira parte do livro seria Odisséia do Vale de Javé.

O fato de Biá precisar dos moradores para rememorar os acontecimentos históricos, registrando assim os fatos heróicos de um povo que justificassem
4. BOTTÉRO, Jean. A escrita e a formação da inteligência na Mesopotâmia Antiga. In: MORRISON, Ken et al. Cultura, pensamento e escrita. São Paulo: Ática, 1995. p. 20-21. 
a sua odisséia, leva-o a procurar pessoas que contassem os grandes feitos do vilarejo. Para dar início à história oficial do vale de Javé, seu Vicentino surge como o iniciador das narrativas históricas e do mito fundador de Javé. E apesar de serem evidentes os diferentes pontos de vista de cada narrador, em todas as narrativas alguns elementos e personagens se mantêm, mesmo que em situações diferentes.

Na primeira narrativa apresentada, o fundador de Javé é o guerreiro Indalécio, que conduz um grupo de pessoas para o que seria a terra prometida. O grupo leva consigo o que possuía de sagrado: um sino a ser colocado na Igreja - marco histórico de Javé. Na narrativa de seu Vicentino, Indalécio é descrito como um guerreiro huno, sempre em cima de seu cavalo, pronto para a guerra.

Para a narradora Deodora, a fundação de Javé foi realizada por Maria Dina, guerreira que levou o povo até as terras de Javé e, do alto da montanha, cantou os limites da cidade. Nessa descrição, Maria Dina se parecia com uma cangaceira.

A terceira versão se dá pela intromissão debochada de Firmino. Entre os risos dos ouvintes e o tom irônico de sua narrativa - pois em sua versão o guerreiro morre de diarréia -, ele diz que Javé nasceu de uma guerra travada entre o povo e a coroa, gente fugida em retirada. Interrompido, discute o fato de sempre nos referirmos ao inimigo como estando na frente. Para ele, trata-se de uma questão geográfica. Da discussão que se segue, outra reflexão histórica: a de que não se pode contar uma história sem o prejuízo da outra.

Para todos, a história para ser científica precisa do documento escrito, precisa de marcas, de provas. Provas e marcas que só aparecem na quarta versão, na discussão sobre as origens, nas referências diretas aos santos Cosme e Damião, nos primeiros objetos que costumamos tratar como fontes históricas, como documentos que fazem da história ciência: a fotografia, os mapas, as ossadas do fundador. Registros visuais que também suscitam análises e comprovações. Vale destacar nessa versão duas frases que nos remetem ao ofício do historiador: o diálogo com as fontes, o exercício da dúvida, o olhar além das aparências. No início da narrativa, os ouvintes são alertados de que a terra vale pelo que produz, mas pode valer mais pelo que esconde.

Finalmente, na quinta versão, o fundador é um guerreiro africano de nome Indaleo. Ele também perambulou por muito tempo com o seu povo até o dia em que encontrou as águas e reencontrou a sua terra de origem: a África/Brasil, considerada por eles parte da África. Aqui o narrador canta a história em dialeto africano e o tradutor tem o nome de Samuel.

O filme de Eliane Caffé foi filmado em Gameleira da Lapa, às margens do Rio São Francisco, na Bahia. Segundo estudiosos das línguas e da cultura brasileira, é considerado o Estado mais afro-negro do Brasil. Relata Silvio Elia

[...] que os próprios negros que conseguiam retornar à terra natal opunham a África à Bahia, como quem quisesse dizer: a África e o resto do mundo. A Bahia 
chegou a ser conhecida como a Nova Guiné e os nativos da Guiné dão o nome de Bahia ao Brasil, a Europa, a América 5 .

Portugal, Brasil, África. Três povos enredados numa história feita de muitas línguas e dialetos, de inúmeras narrativas e um nome fictício: Javé, que, de acordo com Antonio Biá, o único habitante letrado da cidade apresentada no filme de Eliana Caffé, é só um lugar. Para Herrenschmidt, em seus estudos sobre as línguas e os alfabetos dos povos fundadores das culturas e das civilizações humanas, Yavé é um enigma. Enigma da grafia, enigma do nome, enigma de Deus ${ }^{6}$.

Um filme falado, de Manoel de Oliveira, foi filmado sobre as águas do mar Mediterrâneo. Circulador das regiões que deram origem às grandes civilizações e via de acesso entre o Ocidente e o Oriente, mostra-nos, também, o quanto essas culturas, a despeito de toda tradição oral e escrita, estão se distanciando cada vez mais.

Em Narradores de Javé, a hidrelétrica, símbolo do progresso, da tecnologia e do poder, inundou Javé, sua história e memória material. Só restou um objeto: o sino fundador do povoado. Símbolo da fé e da esperança de um povo que, igual a um dos significados de Yavé, "é o ato de fé que aceita a sua existência"7.

Eliane Caffé, para falar de pessoas que querem existir no contexto da história e acreditam que só conseguirão se tiverem uma história escrita, buscou nas memórias de Pedro Cordeiro Braga, narradas na tese de doutorado O Artesão da Memória no Vale do Jequitinhonha ${ }^{8}$ de Vera Felício Pereira, o fio de sua narrativa cinematográfica. Em entrevistas, Caffé conta que Pedro era funcionário de uma Agência de Correio em Uau, Minas Gerais, que ia ser fechada por falta de movimento de cartas. Para mantê-la aberta, ele começou a escrever cartas para várias pessoas, de modo a manter o fluxo. Das correspondências mantidas com Pedro e conversas com Luiz Alberto de Abreu, roteirista do filme, produziram uma ficção que tem no seu contexto a palavra falada, a palavra escrita e, principalmente, uma história de solidariedade, esperança e luta para que o povoado de Javé não seja apenas o lugar ditado por Antonio Biá, mas o cantado por Deodora do alto da montanha, já que, no enigma do nome Yavé, ele pode ser o de uma montanha.

Ao assistirmos Narradores de Javé e Um filme falado podemos entender por que Drummond escrevia que a poesia está no reino das palavras. Como as palavras mudas e sós, em estado de dicionário, as histórias de muitas pessoas e povos também estão esperando para ser escritas em versos ou em prosa. E o cinema, embora traga as narrativas em prosa, não deixa de nos mostrar o quanto as imagens estão repletas de poesia.

Chega mais perto e contempla as palavras.

Cada uma tem mil faces secretas sob a face neutra

e te pergunta, sem interesse pela resposta,

pobre ou terrível, que lhe deres:

- Trouxeste a chave? ${ }^{9}$
5. ELIA, Sílvio. A unidade lingüística do Brasil. Rio de Janeiro: Padrão Editora e Livraria Ltda., 1979. p. 77. 6. HERRENSCHMIDT, Clarisse, op. cit., p. 122.

7. Ibid.

8. PEREIRA, Vera Felício. $\mathrm{O}$ artesão da memória no Vale do Jequitinhonha. Minas Gerais: PUC/Minas. $208 \mathrm{p}$.

9. ANDRADE, Carlos Drummond de, op. cit., p. 214. 


\section{NARRATIVA CINEMATOGRÁFICA. NARRATIVA LITERÁRIA. UMA PROPOSTA DE EXERCÍCIO}

Adoramos ver cinema, discutimos as histórias contadas pelos diretores e roteiristas, gostamos menos ou mais de um determinado gênero, identificamonos com esse ou aquele personagem, conversamos sobre trechos do filme que mais apreciamos, admiramos os efeitos especiais, defendemos algumas idéias apresentadas, rejeitamos outras, enfim, temos sobre a história contada no cinema uma leitura e sabemos falar sobre ela. O que não sabemos é que ao discutirmos um filme estamos fazendo um interessante exercício sobre aspectos da narrativa.

No entanto, embora entendamos que existe uma narrativa no mito, na lenda, na fábula, na pintura, no cinema, nos quadrinhos, percebemos também o quanto é difícil para o professor levar essa discussão para a sala de aula e exercitar a narrativa no campo da literatura, da história ou de uma obra de arte. Buscamos em Benjamin Abdala Jr. ${ }^{10}$ a base teórica dos exercícios sobre narrativas desta seção.

Narradores de Javé e Um filme falado são exemplares para esse exercício, se considerarmos que os dois filmes têm, além da narrativa própria do cinema, as histórias que foram montadas sobre narrativas históricas. Em Um filme falado, Rosa Maria é professora de História e narra as histórias das civilizações para a filha Maria Joana. Em Narradores de Javé, os moradores precisam construir uma história do lugar de tal forma que convença o Estado de que sua narrativa está cientificamente documentada, registrada, o que é feito através da oralidade.

Um primeiro exercício pode ser iniciado: apresentar ao aluno a estrutura da narrativa e por que o conhecimento dela fornece matéria para a argumentação, para uma linha de raciocínio, para a defesa de um ponto de vista, já que ela é construída em torno de uma idéia central, explica-nos Benjamin Abdala Jr. Para o professor, "analisar pressupõe argumentar, defender o ponto de vista crítico que é a sua razão de ser"11.

A partir dos filmes, discutir e ao mesmo tempo explicar o que é um tema e o que é um assunto. Do mesmo modo, apresentar as formas narrativas e, através dos gêneros, como cada um se organiza para contar a história.

Outro aspecto interessante para discussão é a figura do narrador e por que não podemos confundi-la com o autor do filme. Narradores de Javé mostra bem essa diferença, se considerarmos que a autora se inspirou na história real de seu Pedro, carteiro de Uau, em Minas Gerais, e com quem trocou correspondências antes de criar o roteiro (texto) do filme. O professor pode também estender a discussão sobre os diferentes narradores do povoado de Javé, além de trabalhar os significados de leitor e narratário.

Outros aspectos inerentes à estrutura da narrativa e importantes de ser

10. ABDALA JUNIOR, Benjamin. Introdução à análise da narrativa. São Paulo: Scipione, 1995.

11. Id., p. 8. trabalhados são a história e o discurso. No nível da história, Um filme falado é ideal para o aluno entender por que a história na estrutura narrativa é formada pelo conjunto de fatos relatados no conteúdo da narrativa. São fatos fictícios, mas que procuram manter uma relação de verossimilhança com a realidade. 
Assim também é com o discurso, como o plano da expressão do conteúdo. E aqui retomamos Narradores de Javé, ao mostrar como uma determinada história pode ser contada de várias maneiras. Serve também para explicar o foco narrativo como uma das categorias da narrativa e indicar o que são e como se dão a oscilação, as mudanças de foco nos momentos em que cada um dos narradores tem uma versão sobre a fundação e o fundador de Javé.

Quanto ao sumário e a cena, os filmes apresentados são exemplares. Em Narradores de Javé, a autora e diretora delega a narração do filme a um personagem, no caso o autor Nelson Xavier, que apresenta os fatos, representados por sua vez pelos atores.

Sobre a existência da narrativa em diferentes linguagens, vale chamar a atenção dos alunos para uma seqüência de Um filme falado, quando Rosa Maria mostra para a filha uma parede repleta de quadros sobre a história da construção do Canal de Suez. Interessante notar como as três linguagens foram construídas para contar uma mesma história: a narrativa do cinema, a da professora e a da pintura.

Como iniciei este texto com o poema de Carlos Drummond de Andrade e o convite do poeta para que busquemos no reino das palavras a poesia, não poderia deixar de sugerir que o professor chame os alunos para um estudo sobre a riqueza contida nas diferentes línguas existentes no mundo e aproveite para discutir as suas interessantes gramáticas, já que gramática em grego significa $a$ arte de escrever ${ }^{12}$. E como dizia o personagem Biá, quem quiser, que escreva diferente.

Resumo: Como o olhar e o pensamento não são neutros, igual aos olhares dos autores e dos narradores, a autora elege os filmes Narradores de Javé, de Eliane Caffé, e Um filme falado, de Manoel de Oliveira e as narrativas de ambos como foco da atividade de videografia para esta seção. A tentativa é mostrar os diálogos existentes entre diferentes narrativas; as confluências entre a narrativa cinematográfica e as estruturas das narrativas literárias, as possibilidades de pensar sobre as línguas e sobre as escritas que falam e escrevem as histórias e as prosas do mundo. Como as palavras mudas e sós, em estado de dicionário, as histórias de muitas pessoas e povos também estão esperando para ser escritas em versos ou em prosa. E o cinema, embora traga as narrativas em prosa, não deixa de nos mostrar o quanto as imagens estão repletas de poesia.

Palavras-chave: cinema, narrativas, literatura, linguagem cinematográfica.
Abstract: As vision and thinking are not neutral, as the look of authors and narrators, the author chose the motion pictures Narradores de Javé, by Eliane Caffé, and Um filme falado, by Manoel de Oliviera, and the narratives of them both as the focus of this video activity. She tries to show the dialogs that exist between distinct narratives; the confluences between the cinematographic and the literary narratives structures; the possibilities of thinking on languages and on writings that speak and write the histories and proses of the world. With mute and lonely words, in dictionary situation, the histories of many persons and peoples are also waiting to be written in verse or prose. Cinema, though bringing the narrative in prose, shows us the much images are replete of poetry.

Keywords: cinema, narratives, literature, cinematographic language.
12. BAGNO, Marcos. Preconceito lingüístico: o que é, como se faz. São Paulo: Edições Loyola, 2001. 